Document downloaded from:

http://hdl.handle.net/10251/143890

This paper must be cited as:

Broatch, A.; López, JJ.; Garcia Tiscar, J.; Gómez-Soriano, J. (10-2). Experimental analysis of cyclical dispersion in compression-ignited versus spark-ignited engines and its significance for combustion noise numerical modeling. Journal of Engineering for Gas Turbines and Power. 140(10):102808-1-102808-8. https://doi.org/10.1115/1.4040287

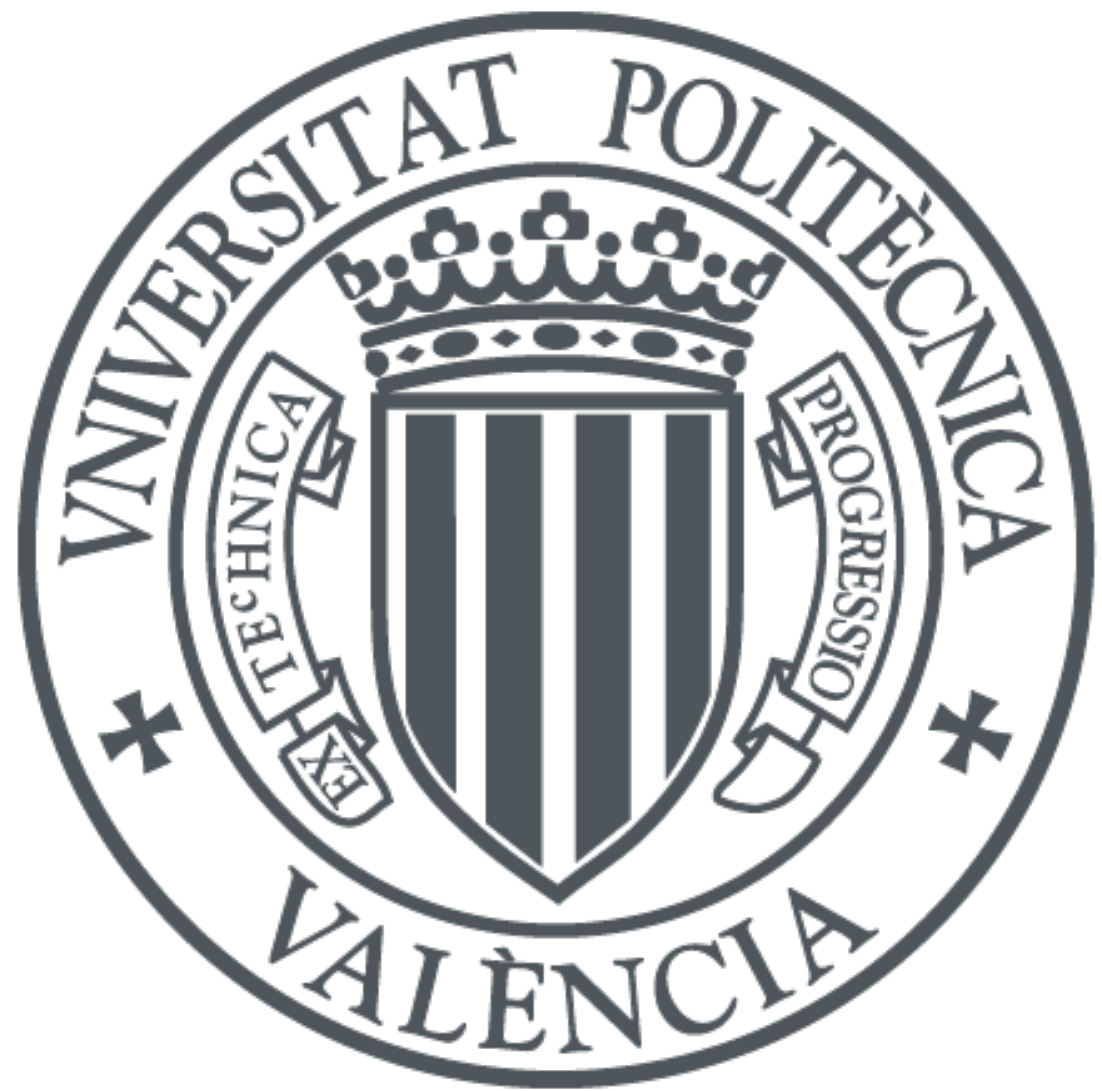

The final publication is available at https://doi.org/10.1115/1.4040287

Copyright ASME International

Additional Information 


\title{
Experimental analysis of cyclical dispersion in compression-ignited versus spark-ignited engines and its significance for combustion noise numerical modelling
}

\author{
A. Broatch ${ }^{\mathrm{a}}$, J. J. López ${ }^{\mathrm{a}}, \mathrm{J}_{\text {. García-Tíscar }}^{\mathrm{a}, *}, \mathrm{~J}_{\text {. Gomez-Soriano }}^{\mathrm{a}}$ \\ ${ }^{a}$ CMT - Motores Térmicos, Universitat Politècnica de València, Camino de Vera, 46022 Valencia, Spain
}

\begin{abstract}
As noise pollution remains one of the biggest hurdles posed by thermal engines, increasing efforts are made to alleviate the generation of combustion noise from the early design stage of the chamber. Since the complexity of both modern chamber geometries and the combustion process itself precludes robust analytic solutions, and since the resonant, highly 3D pressure field is difficult to be measured experimentally, focus is put on the numerical modelling of the process. However, in order to optimize the resources devoted to this simulation, an informed decision must be made on which formulations are followed. In this work, the experimental cyclic dispersion of the in-cylinder pressure is analyzed in two typical compression-ignited (CI) and spark-ignited (SI) engines. Acoustic signatures and pressure rise rates are derived from this data, showing how while the preponderance of flame front propagation and dependency of previous cycle in SI engine noise usually calls for multi-cycle, more complex turbulence modelling such as Large Eddy Simulation (LES), simpler Unsteady Reynolds-Averaged Navier-Stokes (URANS) formulations can accurately characterize the more consistent pressure spectra of CI thermal engines, which feature sudden autoignition as the main noise source.
\end{abstract}

\section{Introduction}

Current approaches for reducing noise levels in internal combustion engines usually involve a good amount of trialand-error, experimental tuning once the combustion chamber design is frozen, or at best a large amount of exploratory parametric permutations, as the geometry of the chamber and the combustion itself are sufficiently complex so as to prevent the development of robust analytical models.

Combustion noise in particular is increasingly relevant as different innovative technologies are being developed such as advanced combustion concepts [1], fuel blending, and so on. While these concepts have the potential of improving efficiency, lowering emissions or reducing the dependency of fossil fuels, their impact [2] on the overall acoustic emission and the perceived engine "quality" by the customer must be carefully evaluated. Therefore, the knowledge about noise fundamentals is essential to analyze the connection between the combustion and the corresponding acoustics.

From a physical point of view, combustion noise is the result of the turbulence and combustion interaction and depending on the application, the contribution of each phenomenon may be completely different. This is particularly relevant in internal combustion engines (ICE), in which the pulsating nature of the sound pressure due to the periodic firing inside the engine cylinders increases the acoustic annoyance [3].

Although ICEs operation can be considered essentially periodic, the instantaneous combustion process in not exactly replicated over consecutive cycles $[4,5]$. This behaviour is

*Corresponding author. Tel.: +34 963877650 .

E-mail address: jorgarti@mot.upv.es (J. García-Tíscar). characterized by a non-repeatability of instantaneous cylinder pressure, commonly refereed to as cycle-to-cycle variation or cyclic combustion variability (CCV), caused principally by the cyclic, turbulent and unsteady character of flow and combustion [6]. It unavoidably appears over the whole operation range, indirectly affecting important engine outputs such as performance and acoustics $[7,8]$. Thus, a proper understanding of the unsteady features of combustion is essential for both identifying the main sources of CCV and minimizing its undesired effects $[9,10]$.

At the same time, in order to optimize the process of the engine design, focus is currently being put on 3D Computational Fluid Dynamics (CFD) simulations of the combustion chamber. Using these models, manufacturers can perform hundreds of parametric studies in parallel without the need of an excessively high number of engine test cells, and characterize the effect of the engine design in the performance, production of pollutants, etc.

Adding to these CFD simulation outputs an accurate estimation of the combustion noise, both in overall terms and in spectral signature that affects customer perception, would allow manufacturers to include this parameter in the design process, optimizing it altogether with the rest of relevant metrics. However, the choice of numerical model should be carefully considered beforehand, as there is a trade-off to be made between computational requirements and accuracy of the simulation.

The solution to this trade-off is not universal, since each case may pose very different challenges. In this paper, the differences between combustion noise produced by CI engines versus that produced by SI engines, which are the most 


\section{Nomenclature}

BMEP brake mean effective pressure

$\mathrm{CCV}$ cycle-to-cycle variation

CFD computational fluid dynamics

CI compression-ignited

DNS direct numerical simulation

EGR exhaust gas recirculation

ICE internal combustion engine

LES large eddy simulation

$\mathrm{NVH}$ noise, vibration and harshness
ON overall noise

PISO pressure implicit with splitting of operator

PRR pressure rise rate

RANS Reynolds-averaged Navier-Stokes

RNG renormalization group

SD standard deviation

SI spark-ignited

SPL sound pressure level

URANS unsteady Reynolds-averaged Navier-Stokes representative internal combustion engine families, are considered. Experimental in-cylinder pressure data is recorded along several cycles for both engines, deriving from this data heat release rates and acoustic spectra, which coupled with cycle-to-cycle dispersion sheds light on how the different combustion processes impact the acoustic behaviour and which are the consequences of these differences when selecting a numerical approach.

\section{Background}

In this section, a very brief introduction is provided to ICE combustion-specific noise, followed by a review of recent investigations on ICE cyclical dispersion.

\subsection{Combustion noise}

The issue of combustion noise in relation to the in-cylinder pressure trace has been studied experimentally for a long time, but it is not until the work of Priede and Grove $[11,12]$ in the decade of 1960 that clear differences are drawn between the raw pressure measured in the chamber along the different engine cycles, that includes the effect of the mechanical compression and the mean combustion pressure rise, and the resonant oscillations inside the combustion chamber specifically caused by the combustion.

While the noise contributions due to the mechanical compression-expansion process are easy to model analytically, and the mean combustion contribution is relatively simple to reproduce by an adequate modelling of the low to middle frequency $[13,14,15,16]$ rise in pressure and temperature, the combustion chamber acoustic resonance remains a more elusive phenomenon to characterize [17].

To gain a better understanding of this complex wave reflection phenomenon, CFD simulations have proved $[18,19,20$, 21] to be a valuable tool, although they are often limited in scope by avoiding actual combustion modelling and focusing instead on synthetic pressure pulses. Thereby, a consensus on the best way to model combustion noise does not yet exist.

\subsection{Cyclic dispersion in combustion}

A variety of studies [22, 7] established the origin of CCV in random fluctuations of a wide range of parameters that can alter the combustion process. The modification of the local conditions of the charge [23], the energy transferred to the fluid during the ignition event (in SI engines), the interaction of the flame kernel with the glow-plug electrodes, and also with the combustion chamber walls, are just a few examples in which the turbulence plays an important role.

However, recent studies made by Finney et al. [6] demonstrated that cyclic variability are not only originated by stochastic fluctuations in the flow field, they postulate that the CCV exhibit a real deterministic behaviour result of the particular conditions reached during the previous cycles. An example of this behaviour is the rebound effect that a partial burning cycle can be succeed by a cycle with a higher expected output due to the unburned fuel present in the residual gases [24].

The most early research on this matter, involving modelling tasks $[25,26,27]$ and the analysis of the most relevant sources [28, 4], focused on SI engine where the cycle variability is considerably more noteworthy than in $\mathrm{CI}$ engines. All of them demonstrated how it is possible to reproduce the main sources of the cyclic variability in a wide range of operating conditions with a LES scheme [29] and an adequate mesh resolution.

These authors also showed, through a statistical analysis of the pressure trace and the brake mean effective pressure (BMEP) parameter, variability values comparable to that observed in the measurements on both stable and unstable conditions: lean mixture, external nitrogen-diluted $\left(\mathrm{N}_{2}\right)$ and knocking-like combustions. According to these findings, simulations under LES schemes can reproduce accurately the phase-averaged mean and dispersion of the in-cylinder pressure, reproducing the stochastic and deterministic variability of the complex phenomena involved in a SI engine combustion.

Other authors [30] showed how a combination of URANS $[31,32]$ with a extremely refined mesh can reproduce the experimentally observed CCV. Results predicted the cyclic variability that comes from the large flow structures variation from one cycle to the next in stable combustion conditions. 
However, in high unstable combustion conditions (misfire due to high EGR dilution), the predicted cyclic variability is not representative of the real engine operation.

Therefore, since URANS can only predict the cyclic variations of the largest flow structures, it is not capable to recreate the stochastic variability of the smallest flow structures, compromising an accurate prediction of the combustion and its effects, specially in unstable combustion regimes. The aftermentioned studies also revealed how the contribution of the deterministic phenomena increases as the combustion stability rises, whereas the stochastic fluctuations due to the turbulence have a crucial contribution in unstable combustion regimes.

In contrast, the research related on the CCV prediction in CI engines is scarce and only a few basic studies were made in URANS schemes [33, 34]. These studies are focused on the cyclic dispersion produced from variability in the operating conditions (e.g. trapped-mass, EGR and other relevant parameters), rather than on cyclic dispersion due to the random behaviour of turbulence and its impact on combustion.

Application of LES schemes [35] in these engine simulations is even more limited, although for instance Tillou et al. [36] proposed a numerical study of the pressure field variability of a single spray combustion into a constant-volume chamber under diesel-like conditions. The results give an idea of the variability of the combustion, specifically on that related to the effect of the stochastic fluctuations in the turbulent flow field.

While the aforementioned studies have shed some light to the main sources of the cyclic variability, clear evidence is still lacking about the advantages of LES in the simulation of this particular issue in CI engines. The remarkably low CCV observed during the steady operating conditions questions if the variability of source phenomena in the flow field is significant. Therefore, a detailed experimental analysis of the CCV is presented in this paper, with the purpose of finding whether it would be feasible to achieve an accurate and representative solution of the acoustic signature of the combustion at a given operating condition with simpler URANS models.

\section{Experimental setup}

In order to obtain representative data for this study, two engines of both CI and SI type have been measured in the test cells available at CMT - Motores Térmicos. The engines were selected taking into account current design trends in the automotive engine market. The main specifications of both engines are included in Table 1.

Both engines have been fully instrumented, including incylinder piezoelectric pressure transducers. This kind of sensor was directly installed at the combustion chamber in the SI engine whereas it was introduced through a glow plug adaptor in the CI engine. Since the latter may add some high-frequency disturbances in the pressure signal due to resonances within the gap between the adapter and the mounting bore, a custom glow plug adapter with reduced gap length (at
Table 1: Engine specifications and operation settings of the engines used in this work.

\begin{tabular}{lll}
\hline Engine type & CI & SI \\
\hline Fuel & Diesel & Gasoline \\
Number of cylinders [-] & 4 & 2 \\
Unitary displacement $\left[\mathrm{cm}^{3}\right]$ & 400 & 300 \\
Bore $[\mathrm{mm}]$ & 75.0 & 70.5 \\
Stroke $[\mathrm{mm}]$ & 88.3 & 76.8 \\
Compression ratio [-] & $18: 1$ & $10: 1$ \\
Engine speed [rpm] & 2000 & 2000 \\
Load [\%] & 68.2 & 97.9 \\
\hline
\end{tabular}

Table 2: Accuracy of the instrumentation used in this work.

\begin{tabular}{lll}
\hline Sensor & Variable & Accuracy [\%] \\
\hline Piezoelectric sensor & In-cylinder pressure & 0.7 \\
Thermocouples & Temperature of all fluids & 0.35 \\
Encoder & Engine speed & 0.006 \\
Piezoresistive sensor & Intake/exhaust pressure & 0.65 \\
Torque meter & Torque & 0.1 \\
Fuel mass flow meter & Fuel mass & 0.2 \\
Air mas flow meter & Air mass & 0.12 \\
\hline
\end{tabular}

the cost of reduced life of the sensor) was designed, ensuring that natural frequencies of the cavity were beyond $35 \mathrm{kHz}$ and thus that acoustic measurements such as those reported in this work $(<20 \mathrm{kHz})$ could be performed free of disturbances.

Additional details of the experimental facilities can be found in previous investigations [37, 38]. In Fig. 1 a schematic of the test cell used for the measurement of the SI engine is provided. The CI engine test cell follows a similar design. Instantaneous pressure data from a single cylinder was acquired at high frequency by means of a Yokogawa oscilloscope, for 50 complete engine cycles, which were enough to correctly characterize CCV without excessive data size. Operation of the engine was controlled by an in-house control system, ensuring that the operating condition was kept constant during the measurement of the cycles. In Table 2 the accuracy of the instrumentation utilized in both experimental facilities are presented as a reference for assessing the uncertainties of measurements.

The working points in both engines, also included in Table 1 , were chosen to be representative of their usual operations, at mid-high levels of speed and load, while at the same time adjusting the precise settings to ensure experimentally that Overall Noise (ON) levels were approximately equal in both cases, approximately $90 \mathrm{~dB}$, in order to perform a meaningful and fair acoustic comparison.

\section{Results and analysis}

In this section, the measured CCV is analysed for both the $\mathrm{CI}$ and SI engines described in the previous section. As a first step, the variability of the in-cylinder pressure is analysed in time and frequency domains in order to identify its main sources. In addition, further insight is sought in the case of 


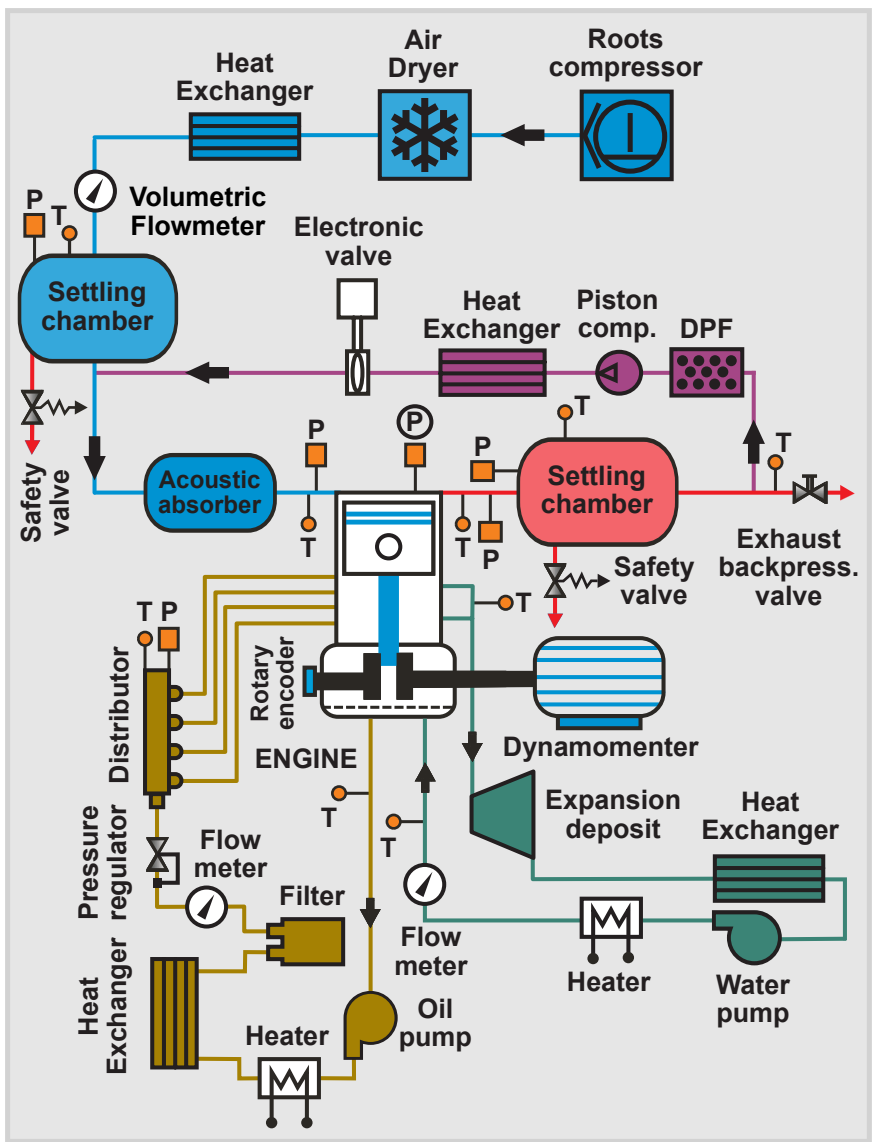

Figure 1: Schematic of the engine test cell used in the measurement of SI combustion cyclical dispersion. In-cylinder pressure traces used in this work were captured with a fast piezoelectric sensor, marked with an encircled "P" symbol

the CI engine by evaluating the CCV of the Pressure Rise Rate (PRR). Finally, the effect of this variability on the external acoustic emission is studied.

\subsection{Pressure trace spectral decomposition}

To begin, experimental pressure data was processed, decomposing the raw pressure trace of each cycle into its components following the technique already pioneered by Priede [11] and further extended by Payri et al. [39, 40]. This is done, first, by subtracting the low-frequency "pseudo-motored pressure trace", exclusively caused by the compression-expansion process itself. Although this signal can be theoretically obtained, it was measured in this work by switching off fuel injection in just the studied cylinder during one isolated cycle while the combustion was kept in the other cylinders [39]. This procedure was repeated six times through the 50 recorded cycles, thereby allowing to estimate an average pseudo-motored signal while the operating conditions were maintained.

Once that this purely mechanical contribution is subtracted, the "excess" pressure signal that remains is related to the combustion process $[41,42]$. From the point of view of the frequency, now it is possible to determine a cut-off frequency between both signals. As it can be seen in Figure 2, in which data from CI engine is plotted as an example, the spectrum of pseudo-motored signal practically matches the averaged spectrum in the low frequency range. The difference among both traces (b-c) plotted in light red in the bottom graph of this figure, reveals that the minimum gap is around $0.4 \mathrm{kHz}$. This frequency was therefore considered as the first cut-off frequency for the CI engine. A similar value $(0.43 \mathrm{kHz})$ was obtained for the SI engine by applying the same procedure.

An additional difference must be established however between the homogeneous pressure rise caused by the heat release of the combustion, and the resonant gas oscillations inside the chamber caused by the reflections of the pressure waves [18, 19, 37]. This resonance-dominated part of the pressure spectra can be isolated through a high-pass filter, the cut-off frequency of which can be determined following the method suggested by Strahle [13] for diesel engines, where the spectrum of the cycle-averaged pressure trace (instantaneous mean of the 50 recorded cycles) is compared to the average of all 50 spectra. When a significant difference appears between both traces at a certain frequency, then this can be regarded as the start of the frequency range dominated by the resonant pressure wave oscillations. As it can be seen in Fig. 2, this frequency for the CI engine was determined by the point at which the gap between both traces exceeds $1 \%$ of difference.

Regarding the cut-off between these two combustion contributions in the SI engine, the observed large CCV makes it more difficult to distinguish between them and it also evinces

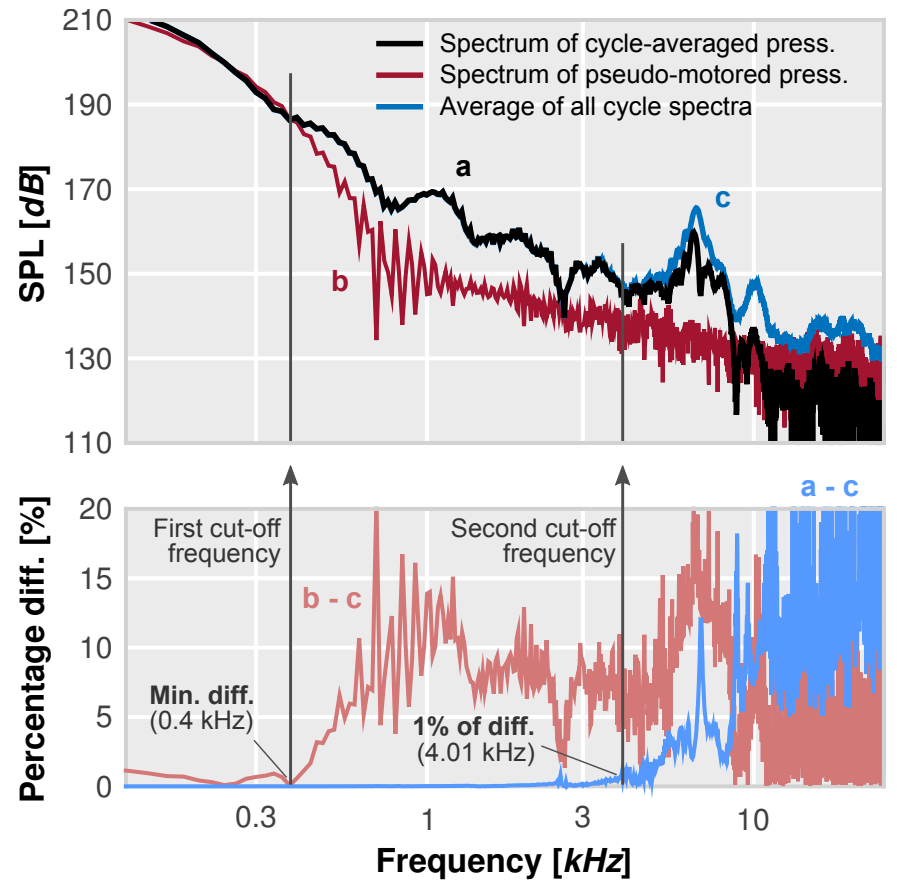

Figure 2: Visual representation of the frequency cut-off determination following the selected pressure decomposition algorithm. 
that the criterion used in CI cannot be applied. Therefore the frequency cut-off point of the resonance range has been kept between both engines in order to facilitate the comparison.

The result of applying this decomposition procedure to the experimental engine data can be seen in Fig. 3. In the top plot, the CI engine in-cylinder pressure is shown. Raw pressure from a selected test can be seen in green, accompanied by its corresponding components: mechanical compression in red, mean combustion pressure in black, and the chamber resonant oscillations in blue. CCV has been included in these curves by shading representing the standard deviation (SD) at each crank angle.

It can be seen that cyclical dispersion is low in this engine, even when looking at the oscillations caused by the pressure resonance in the chamber. Moreover, the dispersion does not alter the oscillation pattern, which is maintained as a selfsimilar process. The shape of the combustion pressure trace is also constant along the different cycles.

On bottom plot of the same figure, data from the SI engine is shown following the same decomposition procedure. In this case, CCV is significantly larger than in the CI engine, both in
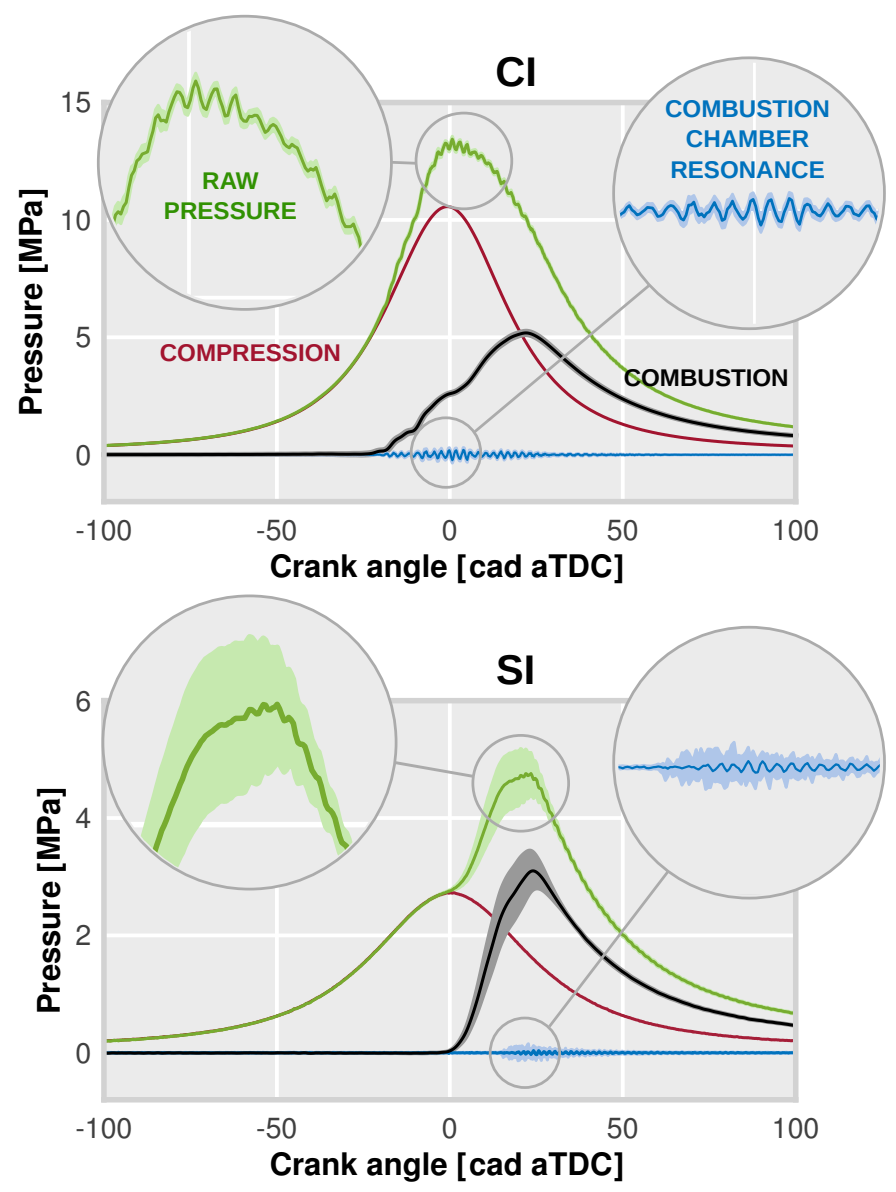

Figure 3: Time evolution of the pressure traces in both engines: CI (top plot) and SI (bottom plot). Besides raw pressure, each contribution to the pressure is also included, along with their standard deviation (shaded). Zoomed views are provided highlighting the oscillations of the chamber resonance the mean combustion pressure trace and in the oscillations caused by the resonance in the chamber. Notably, dispersion in the later, shown in the zoomed view, causes some cycles to have very different oscillations than the sample cycle shown in blue.

In Fig. 4 the same information has been plotted in the frequency domain by calculating the spectrum of each decomposed pressure signal. This allows the quantification of the CCV for each frequency, showing again the different pressure contributions. In the case of the CI engine, CCV is only apparent on the resonant range, and even in this case the clear peaks already identified by Priede [12] remain unaffected by the dispersion. At the medium frequency range dominated by the mean combustion pressure between 0.4 and $4 \mathrm{kHz}$ almost no CCV can be detected.

In the SI engine shown in the bottom plot, where the pressure rate is not so sudden and the heat release is more progressive, CCV is much larger. Dispersion is already clearly detected even at the lower $0.4 \mathrm{kHz}$ mark, being prominent even in the pure combustion phase before the resonance frequency range.

Inspection of the in-cylinder pressure spectra often reveals a constant slope region following the mechanical pressure component that then ends with a flat spectrum region (see
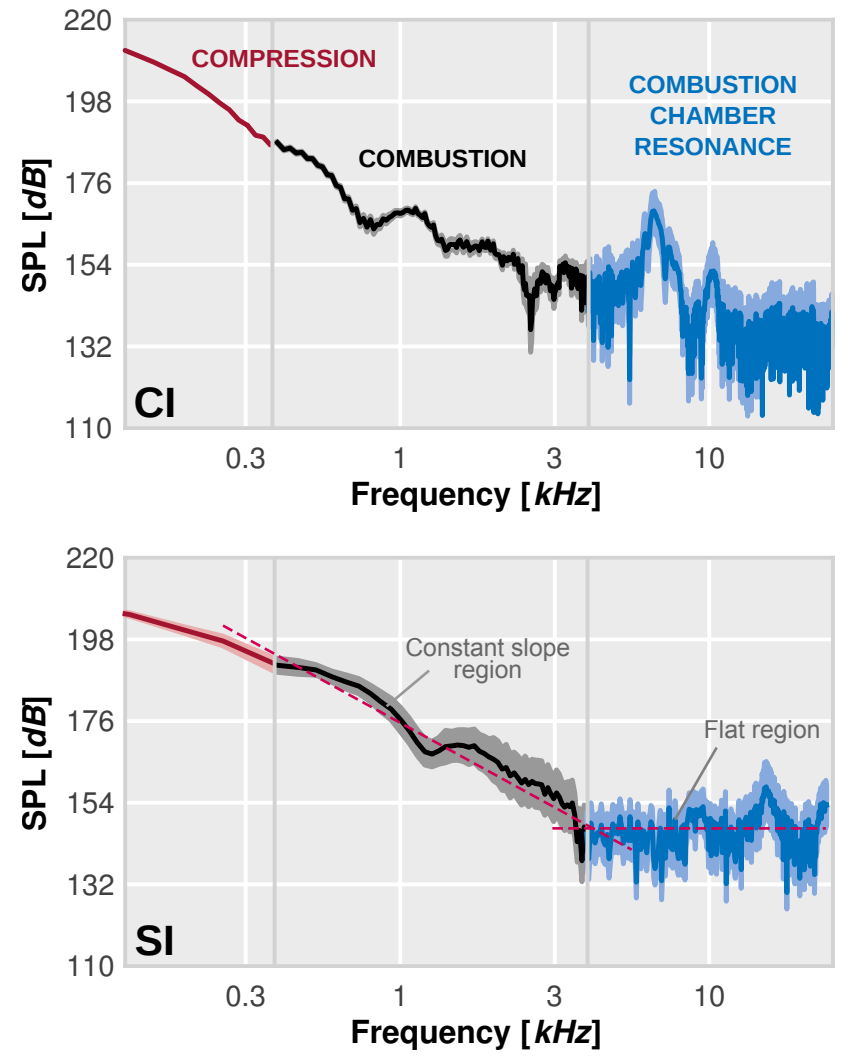

Figure 4: Pressure spectral density in both engines: CI (top plot) and SI (bottom plot). Spectra have been separated based on the prevalence of each source mechanism, including the mean sound pressure level (SPL) and the standard deviation (shaded) along all experimental cycles 
bottom graph of Fig. 4). This turning point, which in this case is also close to $4 \mathrm{kHz}$, can be regarded as the cut-off frequency where the direct effect of combustion in the pressure spectra vanishes and only resonant pressure fluctuations in the chamber remain, without further excitations due to combustion. If this singular behaviour would be reproduced at all operation conditions, it could be considered an appropriate criterion to establish the second cut-off frequency in SI engines.

While a resonance peak is also visible in the SI spectra, its frequency is an order of magnitude higher than that of the $\mathrm{CI}$ engine, peaking around $15 \mathrm{kHz}$ where the attenuation of both the human hearing system and the engine block itself are much higher. Thereby, this resonance peak is of much lower relevance regarding acoustic emission than the ones identified in the CI engine, in which resonance peaks are located at 6.7 and $10 \mathrm{kHz}$.

Data shown in these figures already illustrates the reason behind the prevalence of LES turbulence modelling in simulations of SI engines, since the high variability of the pressure traces inside the chamber makes the accurate resolution of local oscillation necessary for the successful reproduction of the combustion process.

On the other hand, the experimental data attests the stability of CI combustion. Fig. 4 shows how the mean pressure rise caused by the combustion process itself features almost no CCV, with almost all the dispersion constrained to the higher frequency of the spectrum where wall reflections are responsible for complex resonant features.

Thus, a turbulence model capable of reproducing the macroscopic mean features rising from the combustion heat release, along with the pressure wave motion and reflection, should be able to successfully resolve these acoustic resonant phenomena. For instance, Renormalization Group (RNG) $k-\varepsilon$ models, resolved through a Pressure Implicit with Splitting of Operator (PISO) algorithm, have been demonstrated in the literature to correctly predict relevant processes of CI combustion such as injection and autoignition, [43] rate of heat release [44] and pressure wave propagation and reflection through the chamber [18].

\subsection{Pressure rise rate analysis}

However, the question remains as to what advantage could be gained from switching to a more realistic LES turbulence model. Literature is yet scarce on LES simulations of ICEs, and the published research is mostly related to SI engines. Trying to identify the most relevant sources of CCV seems to be a common concern.

An analysis of the PRR, this is, dp/dt from the measured cycles, may shed some light on CCV sources for the two different engines. For this purpose, in Fig. 5 the PRR has been plotted along its cycle-to-cycle standard deviation for both engines considered so far. The two axes of both graphs were normalized by the same factor in order to allow a fair comparison between the engines. Hence PRR was normalized by the maximum PRR registered in the SI engine, which corresponds to the maximum PRR recorded along the two tests.
The temporal gap is identical in both graphs: zero coincides with the start of the CI combustion while the upper value was adjusted to guarantee a proper visualization of relevant data.

Focusing on the CI results displayed in the top plot, the contribution of each of the three combustions (two pilots and a main one) to the PRR can be clearly seen. Within the pilot injection stages, two peaks can be clearly identified; the maximum being related to the premixed combustion whereas the other is a direct consequence of a short diffusion burning phase. In the main injection phase however, only a soft change in the slope delimits the transition between premixed and mixing-dominated phases.

Moreover, it can be noticed that the largest cyclical SD is located at the peaks of the premixed combustions, with approximately $8 \% \pm \mathrm{SD}$. At the diffusion combustion phases however, \pm SD descends to approximately $4 \%$. Prior to the combustion, \pm SD is only $0.2 \%$. This is, dispersion magnitude in the combustion phase appears to be around one order of magnitude higher than that of the purely mechanical processes such as variations of the injected fuel quantity, trapped mass, deformations, heat transfer, etc.

Tillou et al. [36] simulated an environment where only consecutive combustions of a diesel spray were considered by using a LES scheme; since no mechanical compression or air scavenging are taking place, only the variance due to the combustion itself was present.
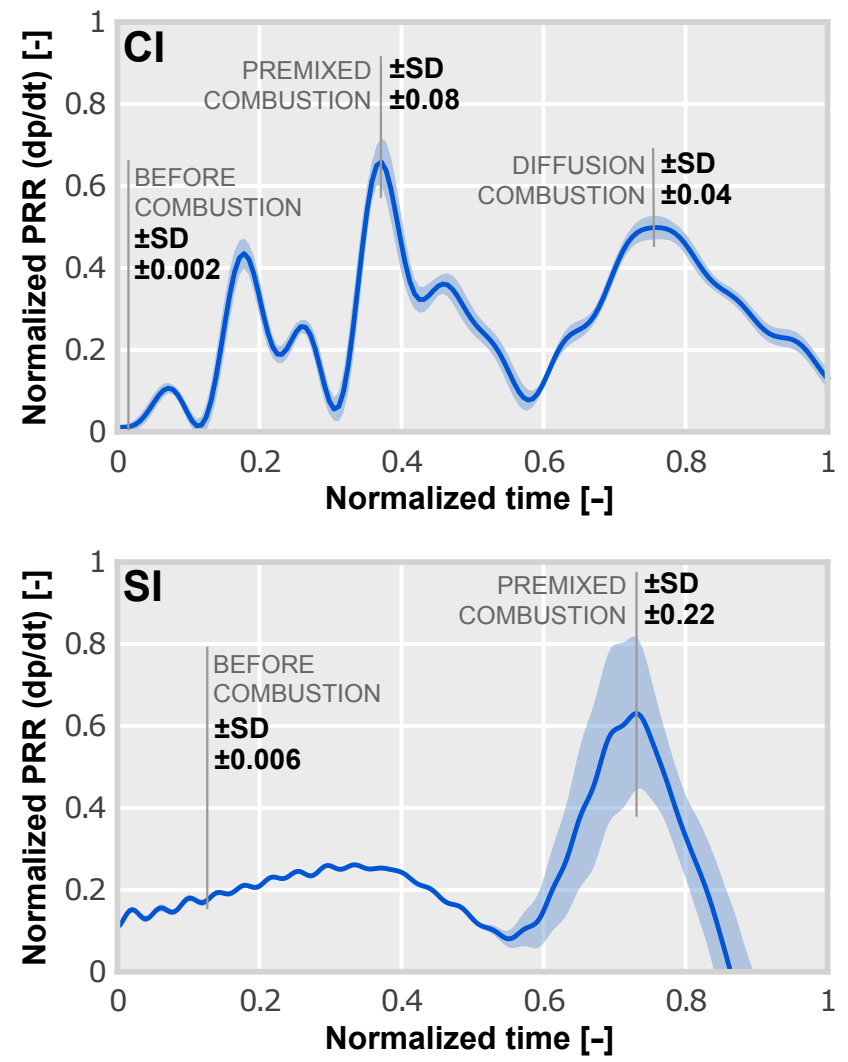

Figure 5: Normalized PRR measured in the CI engine (top) and the SI engine (bottom) along with its standard deviation (shaded) 
Comparing the experimental CI engine PRR observed in Fig. 5 (top) and Tillou et al. results, which show that the maximum variation of the PRR during this process is approximately $5 \%$ (and thus, that \pm SD is be even lower), appears to confirm that LES of CI combustion does not account for all CCV sources, since in the CI case CCV is low enough that the contribution of mechanical processes, which are difficult to simulate, is not insignificant.

On the other hand, the bottom plot of Fig. 5 shows the normalized PRR obtained from the SI engine data. It can be easily seen that the maximum dispersion is substantially higher in this case, since the maximum standard deviation reaches values of $22 \%$, even though the maximum value of the cycle-averaged PRR is close to that observed in the previous engine.

This fact highlights the completely different phenomena involved in both engine concepts. In the SI case, some authors [27, 26] have proved that local flow changes associated to turbulent fluctuations become the major source of CCV, rendering the effects of the system clearances secondary.

In fact, comparing the CCV prior to combustion in the bottom plot of Fig. 5, it can be seen that the dispersion at the combustion phase is two orders of magnitude larger, remarking the value of the more comprehensive LES simulation in the SI case.

\subsection{Overall noise CCV}

Once that we have evaluated which sources can affect the variability of the pressure field, we can estimate how this source phenomenon translates to the externally-radiated noise, taking into account the attenuation due to the engine structure which is highly non-linear and time dependent [46].

For qualitative analysis many research works estimate the acoustic path between the source and free-field conditions by a transfer function. This simplification does not allow for an accurate prediction of the radiated noise level [37, 47], but it is extremely useful for relative comparisons [48, 49]. Besides, several combustion noise metrics are defined following this method.

In this case, the acoustic path was estimated with the classical approach proposed by Austen and Priede [45], which assumes a linear behaviour between the source and the observer. According to this theory, the engine structural attenuation curve can be calculated as the difference between the in-cylinder pressure and the radiated noise 1/3-octave band spectra. Among all structural attenuation curves available in the literature [50, 51, 37], the one obtained by Anderton [50] in the early 80's was selected to estimate the spectrum of the radiated noise, as it is one of the most extended.

Combining both approaches it is possible to estimate the overall engine noise (ON) of any operation condition as

$$
\mathrm{ON}(\mathrm{dB})=10 \cdot \log _{10} \frac{P_{N}^{2}}{p_{0}^{2}}
$$

where $p_{0}$ is a reference sound pressure of $20 \mu \mathrm{Pa}$, which corresponds to the minimum human hearing threshold and $P_{N}$ is defined as

$$
P_{N}=\frac{1}{N} \cdot \sum_{f=f_{1}}^{f_{N}} P(f)
$$

where $N$ is the number of harmonics between $f_{1}$ and $f_{N}$, and $P(f)$ represents the Fast Fourier Transform (FFT) of the engine radiated signal, which is obtained by subtracting the structural attenuation curve [50] from the in-cylinder pressure spectrum following Austen's approach [45].

In Fig. 6 the overall noise obtained for each engine cycle is plotted together with two common statistical values, the mean and the standard deviation. As expected, the cyclic dispersion of this parameter follows the same trend observed in the pressure trace, it is considerably larger in the SI engine than in the CI one.

Even though the levels of overall noise in both engines were kept similar during the measurements (89.61 dB in CI vs. $90.59 \mathrm{~dB}$ in $\mathrm{SI}$ ), the standard deviation is significantly higher in the SI engine, with $3.12 \mathrm{~dB}$ of deviation against the $1.47 \mathrm{~dB}$ measured in the $\mathrm{CI}$ engine.
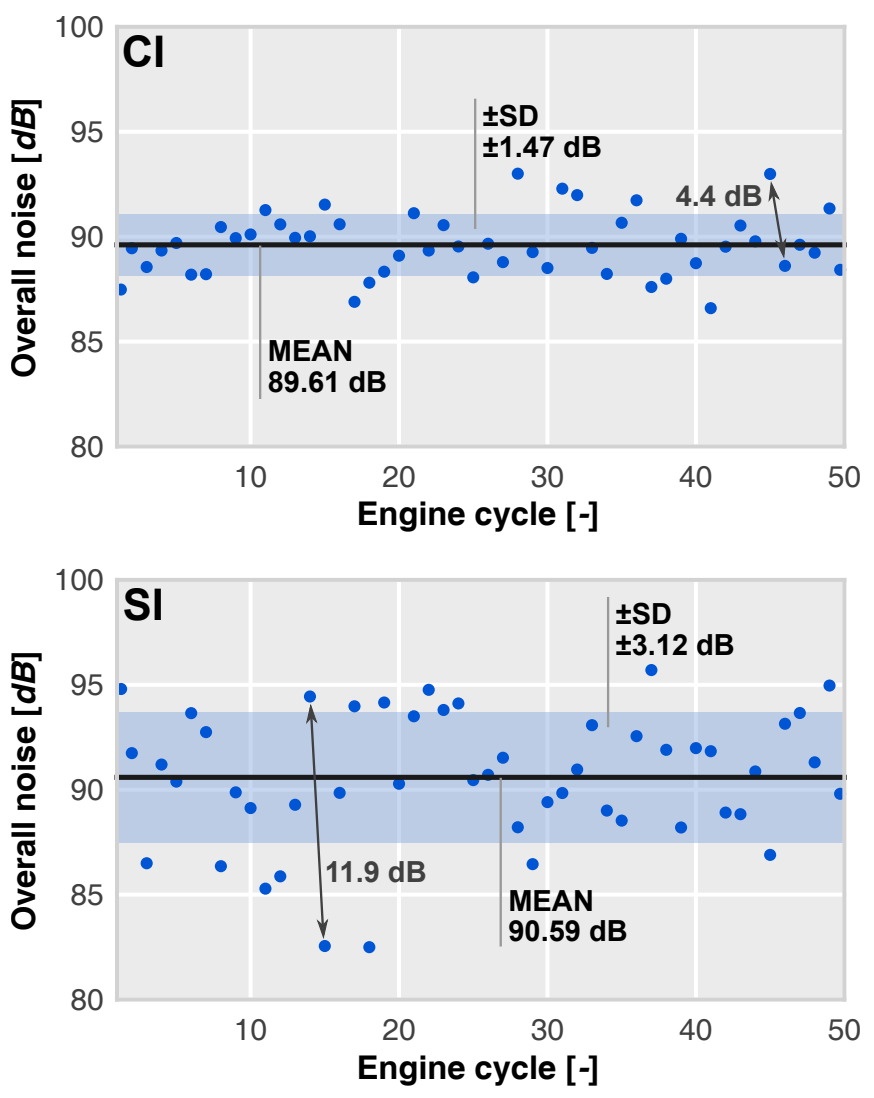

Figure 6: Cyclic variability of the overall engine noise obtained by the classical approach proposed by Austen and Priede [45] in both engines: CI (top plot) and SI (bottom plot). ON level of each cycle is plotted (dots) along with the mean (solid black line) and standard deviation (shaded) 
The fact that almost all CI cycles are close to the mean in terms of noise confirm that the small variations of the combustion-related phenomena have a lesser impact on the acoustic emission of CI engines. This also supports the use of URANS schemes in this case, since a certain simulated cycle can be very representative of the overall cycle-to-cycle operation.

On the other hand, large cycle-to-cycle variations in terms of acoustic output can be observed in the SI engine, up to $11.89 \mathrm{~dB}$ from the $94.44 \mathrm{~dB}$ of cycle 14 to the $82.55 \mathrm{~dB}$ of cycle 15 . This suggests that multiple cycle simulations should be conducted when aiming to characterize the noise level of SI engines, a task for which LES models are much more appropriate.

\section{Discussion}

Experimental results presented herein show how inside the CI engine cycle a complete oscillatory process, identified as combustion chamber resonance, takes place from start to finish, and that this oscillatory process is self-similar: there is some cycle-to-cycle dispersion, but all resonant peaks are conserved through the operation of the engine. This shows that the macroscopic pressure wave propagation and interaction process repeats in almost the same way for each cycle. On the other hand, data from the tested SI engine shows how the increased CCV typical of these engines can drown out the resonance signal.

In terms of pressure spectral density data obtained through component decomposition techniques, clear resonance peaks have been detected for the CI engine at mid-level frequencies that are known to be less attenuated by the mechanical structures and by the human hearing itself. In the case of SI combustion noise, a single, weaker resonant peak has been shown at a higher frequency, which is thus more attenuated naturally.

Influence of CCV in the acoustic signature of the engine has also been demonstrated through a decomposition procedure, showing how CCV of CI engines is confined to the resonant region of the spectrum while in the case of SI engines even low frequencies typical of the mean combustion pressure boost present significant CCV.

Additional insight on CI CCV has been attained by analysing the dispersion of PRR data, that highlights the contributions of each combustion to the pressure boost. Comparison of the magnitude of PRR CCV evolution, combined with published LES data of repeated CI-like combustion in an idealized environment, suggests that while dispersion in the pressure excitation due to the combustion process itself is dominant, mechanical effects in CI are only one order of magnitude lower. This is thus the limit of improvement in CI noise CCV simulation, as mechanical effects are notoriously difficult to consider in numerical model.

Furthermore, the effect of these variations in the pressure field on the overall noise has been experimentally demonstrated. As the operating point of both engines was selected to achieve the same overall noise level, it is easy to notice how the SI engine features a much larger variation of acoustical output between consecutive cycles.

These experimental observations are significant regarding the simulation of combustion noise generation by a particular engine. Self-similarity of CI resonance, coupled with low combustion contribution dispersion, suggests that the analysis of a single engine cycle is sufficient to understand its acoustic behaviour.

Plus, the major contributors to the CI resonant field are sudden pressure waves produced by the autoignition of the fuel-air mixture that then travel and reflect within the chamber. Hence, URANS numerical schemes that have been demonstrated to properly resolve CI injection, combustion and pressure wave oscillations are suggested to model the acoustics of a CI cycle which, as demonstrated experimentally in this work, will be then sufficiently representative of subsequent cycles.

In the case of the SI engine however, where large CCV is demonstrated, results show how this increased dispersion has a significant influence on the acoustic output. The SI noise signature is affected by CCV not only in the resonance phase but also in the combustion-dominated part of the spectrum. Cycle-to-cycle radiation noise estimation attests this variability, with large differences identified between the ON of consecutive cycles.

These facts suggest that when numerical simulation of SI combustion acoustics is sought, the selected turbulence model should be able to properly resolve not only the sudden pressure boost of the ignition as in the CI case but also the dynamics of the flame propagation and, in addition, the variability between consecutive cycles. Hence, LES schemes should be preferable when simulating SI acoustics, since its preservation of unsteady components of pressure, velocity and temperature from one cycle to the next allow more realistic combustion conditions.

As shown in this paper, noise data from single SI cycle is not guaranteed to be representative, and several cycles should therefore be measured or simulated in order to obtain a realistic mean ON level. Moreover, it should be noted that the results presented herein are representative of steady operating conditions, whereas if engine transients are to be considered, CCV would be even more significant, exacerbating [52] the noise issues discussed in this work and reinforcing the need for multi-cycle measurements and simulations.

\section{Conclusions}

In this investigation, experimental measurements of instrumented ICEs belonging to the two most popular combustion concepts, CI and SI, operating at the same ON level, have allowed a comparison of their different cyclical dispersion characteristics from the point of view of acoustical emission, a critical factor given the increased market and regulator pressure on combustion vehicles. 
Combined with a review of the two main approaches for the numerical modelling of ICEs, which is a crucial step in the design process and also in the understanding of the noise source behaviour, the following conclusions have been reached:

1. Spectral decomposition of the pressure traces reveals that in the case of CI engines the combustion contribution to the pressure trace CCV is very low, being chamber resonance the main source. However, the analysis reveals that acoustic resonance in modern CI chambers is a self-similar process.

2. Results from the SI engine analysis show higher dispersion already in the combustion contribution, with no self-similarity of the acoustic resonance. Translated to radiated $\mathrm{ON}$, levels are shown to vary significantly.

These experimental findings allow the establishment of some recommendations on the choice of turbulence modelling in ICE acoustic simulations:

1. A well-configured ${ }^{1}$ single-cycle URANS simulation can offer representative CI noise spectra. This is of special relevance for industrial applications.

2. However, LES schemes capable of improved CCV reproduction are advised if comprehensive acoustic characterization of SI engines is sought through numerical means.

\section{Future works}

In order to further confirm the conclusions reached in this investigation about the influence of CCV in acoustic prediction by numerical simulations, especially in the case of CI engines where the cost of multi-cycle LES appears to be questionable for $\mathrm{ON}$ and spectra prediction, work is underway to produce a representative comparison between an URANS and a LES simulation of the same CI engine.

\section{Acknowledgements}

The equipment used in this work has been partially supported by FEDER project funds "Dotación de infraestructuras científico técnicas para el Centro Integral de Mejora Energética y Medioambiental de Sistemas de Transporte (CiMeT)" [grant number FEDER-ICTS-2012-06], framed in the operational program of unique scientific and technical infrastructure of the Spanish Government. J. Gomez-Soriano is partially supported through the Programa de Apoyo para la Investigación y Desarrollo (PAID) of Universitat Politècnica de València [grant number FPI-S2-2016-1353].

${ }^{1}$ This is, with a space and time discretization small enough to correctly resolve the pressure waves travelling and interacting within the chamber.

\section{References}

[1] A. Torregrosa, A. Broatch, R. Novella, L. Mónico, Suitability analysis of advanced diesel combustion concepts for emissions and noise control, Energy 36 (2) (2011) 825-838. doi:10.1016/j.energy.2010.12. 032.

[2] E. Scheie, F. Pischinger, U. Reuter, Preinjection-a measure to influence exhaust quality and noise in diesel engines, J Eng Gas Turb Power 111 (1989) 445. doi:10.1115/1.3240274.

[3] M. Nor, M. Fouladi, H. Nahvi, A. Ariffin, Index for vehicle acoustical comfort inside a passenger car, Appl. Acoust. 69 (4) (2008) 343-353. doi: 10.1016/j . apacoust. 2006.11.001.

[4] N. Ozdor, M. Dulger, E. Sher, Cyclic variability in spark ignition engines a literature survey, SAE Technical Paper 940987. doi : 10.4271/940987.

[5] T. D. Fansler, R. M. Wagner, Cyclic dispersion in engine combustionIntroduction by the special issue editors, Int. J. Engine Res. 16 (3) (2015) 255-259. doi:10.1177/1468087415572740.

[6] C. E. Finney, B. C. Kaul, C. S. Daw, R. M. Wagner, K. D. Edwards, J. B. Green Jr, A review of deterministic effects in cyclic variability of internal combustion engines, Int. J. Engine Res. 16 (3) (2015) 366-378. doi: $10.1177 / 1468087415572033$.

[7] K. Schmillen, J. Wolschendorf, Cycle-to-cycle variations of combustion noise in diesel, SAE Technical Paper 890129. doi: 10.4271/890129.

[8] A. Acri, E. Nijman, M. Klanner, G. Offner, R. Corradi, On the influence of cyclic variability on surface noise contribution analysis of internal combustion engines, Appl. Acoust. 132 (C) (2018) 97-108. doi: 10 1016/j . apacoust. 2017.11.012.

[9] T. D. Fansler, D. L. Reuss, V. Sick, R. N. Dahms, Invited review: Combustion instability in spray-guided stratified-charge engines: A review, Int. J. Engine Res. 16 (3) (2015) 260-305. doi:10.1177/ 1468087414565675.

[10] W. Zeng, M. Sjöberg, D. L. Reuss, Piv examination of spray-enhanced swirl flow for combustion stabilization in a spray-guided stratifiedcharge direct-injection spark-ignition engine, Int. J. Engine Res. 16 (3) (2015) 306-322. doi:10.1177/1468087414564605

[11] T. Priede, Relation between form of cylinder-pressure diagram and noise in diesel engines, P. I. Mech. Eng.: Automobile Division 14 (1) (1960) 63-97. doi:10.1243/pime_auto_1960_000_012_02.

[12] T. Priede, E. Grover, Paper 2: Noise of industrial diesel engines, P. I. Mech. Eng., Conference Proceedings 181 (3) (1966) 73-89. doi: 10.1243/pime_conf_1966_181_062_02.

[13] W. C. Strahle, Combustion randomness and diesel engine noise: theory and initial experiments, Combust. Flame 28 (1977) 279-290. doi: 10. $1016 / 0010-2180$ (77) $90033-5$.

[14] N. J. Boesch, The Development of Low-Noise DI Diesel Engines, SAE Technical Paper 870951. doi : 10.4271/870951.

[15] C. Kavuri, S. Singh, S. R. Krishnan, K. K. Srinivasan, S. Ciatti, Computational analysis of combustion of high and low cetane fuels in a compression ignition engine, J Eng Gas Turb Power 136 (12) (2014) 121506. doi: 10.1115/1.4027927.

[16] S. Busch, K. Zha, A. Warey, F. Pesce, R. Peterson, On the reduction of combustion noise by a close-coupled pilot injection in a small-bore direct-injection diesel engine, J Eng Gas Turb Power 138 (10) (2016) 102804. doi : 10.1115/ICEF2015- 1004.

[17] R. Hickling, D. A. Feldmaier, S. H. Sung, Knock-induced cavity resonances in open chamber Diesel engines, J. Acoust. Soc. Am. 65 (5) (1979) 1474-1479. doi:10.1121/1.382910.

[18] A. J. Torregrosa, A. Broatch, X. Margot, V. Marant, Combustion chamber resonances in direct injection automotive Diesel engines: a numerical approach, Int. J. Engine Res. 5 (1) (2003) 83-91. doi: 10. 1243/146808704772914264.

[19] A. Broatch, X. Margot, A. Gil, C. Donayre, Computational study of the sensitivity to ignition characteristics of the resonance in DI diesel engine combustion chambers, Eng. Computation. 24 (1) (2007) 77-96. doi : 10.1108/02644400710718583.

[20] A. J. Torregrosa, A. Broatch, A. Gil, J. Gomez-Soriano, Numerical approach for assessing combustion noise in compression-ignitied Diesel engines, Appl. Acoust. 135 (2018) 91--100. doi : 10.1016/j . apacoust. 2018.02.006. 
[21] A. J. Torregrosa, A. Broatch, J. García-Tíscar, J. Gomez-Soriano, Modal decomposition of the unsteady flow field in compression-ignited combustion chambers, Combust. Flame 188 (2018) 469-482. doi:10. 1016/j . combustflame . 2017.10.007.

[22] M. B. Young, Cyclic Dispersion in the Homogeneous-Charge SparkIgnition Engine-A Literature Survey, SAE International Congress and Exposition 810020. doi : 10.4271/810020.

[23] P. S. Abraham, X. Yang, S. Gupta, T.-W. Kuo, D. L. Reuss, V. Sick, Flowpattern switching in a motored spark ignition engine, Int. J. Engine Res. 16 (3) (2015) 323-339. doi : 10.1177/1468087414565400.

[24] B. Wu, Y. Ma, X. Yu, W. Gu, Y. Li, W. Su, Effects of exhaust gas recycle loop layout and retarded intake valve closing on variations in combustion in a heavy-duty diesel engine, Int. J. Engine Res. 16 (3) (2015) 340-355. doi: 10.1177/1468087414555731.

[25] O. Laget, B. Reveille, L. Martinez, K. Truffin, C. Habchi, C. Angelberger, LES Calculations of a four cylinder engine, SAE Technical Paper 201101-0832. doi:doi:10.4271/2011-01-0832.

[26] K. Truffin, C. Angelberger, S. Richard, C. Pera, Using large-eddy simulation and multivariate analysis to understand the sources of combustion cyclic variability in a spark-ignition engine, Combust. Flame 162 (12) (2015) 4371-4390. doi : 10.1016/j . combustflame. 2015.07.003.

[27] A. Misdariis, O. Vermorel, T. Poinsot, Les of knocking in engines using dual heat transfer and two-step reduced schemes, Combust. Flame 162 (11) (2015) 4304-4312. doi:10.1016/j . combustflame. 2015 07.023.

[28] G. M. Rassweiler, L. Withrow, W. Cornelius, Engine Combustion and Pressure Development-Effects of Mixture Ratio, Spark Position, and Throttle Opening on Flame Pictures and Pressure Cards, SAE Technical Paper 400127. doi : 10.4271/400127.

[29] S. B. Pope, Ten questions concerning the large-eddy simulation of turbulent flows, New J. Phys. 6 (1) (2004) 35. doi : 10 . 1088/1367 - 2630/ $6 / 1 / 035$.

[30] R. Scarcelli, K. Richards, E. Pomraning, P. Senecal, T. Wallner, J. Sevik, Cycle-to-Cycle Variations in Multi-Cycle Engine RANS Simulations, SAE Technical Paper 2016-01-0593. doi : 10. 4271/2016-01-0593.

[31] V. Yakhot, S. Orszag, Renormalization group analysis of turbulence., J. Sci. Comput. 1 (1) (1986) 3-51. doi : 10 . 1007/BF01061452.

[32] D. C. Wilcox, Formulation of the k-w turbulence model revisited, AIAA journal 46 (11) (2008) 2823-2838. doi : 10.2514/1.36541.

[33] D. Klos, S. L. Kokjohn, Investigation of the sources of combustion instability in low-temperature combustion engines using response surface models, Int. J. Engine Res. 16 (3) (2015) 419-440. doi: 10.1177/1468087414556135.

[34] M. Jia, A. B. Dempsey, H. Wang, Y. Li, R. D. Reitz, Numerical simulation of cyclic variability in reactivity-controlled compression ignition combustion with a focus on the initial temperature at intake valve closing, Int. J. Engine Res. 16 (3) (2015) 441-460. doi: 10.1177/1468087414552088.

[35] J. Smagorinsky, General circulation experiments with the primitive equations, Monthly Weather Review 91 (3) (1963) 99-164. doi : 10. 1175/1520-0493 ( 1963) 091<0099: GCEWTP>2 . 3. C0; 2 .

[36] J. Tillou, J.-B. Michel, C. Angelberger, D. Veynante, Assessing les models based on tabulated chemistry for the simulation of diesel spray combustion, Combust. Flame 161 (2) (2014) 525-540. doi: 10.1016/j . combustflame. 2013.09.006.

[37] A. Torregrosa, A. Broatch, J. Martín, L. Monelletta, Combustion noise level assessment in direct injection diesel engines by means of incylinder pressure components, Meas. Sci. Technol. 18 (7) (2007) 2131. doi : 10. 1088/0957-0233/18/7/045.
[38] J. J. López, S. Molina, A. García, J. Valero-Marco, F. Justet, Analysis of the potential of a new automotive two-stroke gasoline engine able to operate in spark ignition and controlled autoignition combustion modes, Appl. Therm. Eng. 126 (2017) 834-847. doi: 10. 1016/j . applthermaleng . 2017.07.213.

[39] F. Payri, A. Broatch, B. Tormos, V. Marant, New methodology for incylinder pressure analysis in direct injection diesel engines-application to combustion noise, Meas. Sci. Technol. 16 (2) (2005) 540. doi: 10. 1088/0957-0233/16/2/029.

[40] F. Payri, A. Broatch, X. Margot, L. Monelletta, Sound quality assessment of diesel combustion noise using in-cylinder pressure components, Meas. Sci. Technol. 20 (1) (2008) 015107. doi : 10. 1088/0957-0233/ 20/1/015107.

[41] J. Yang, R. Anderson, A new criterion for judging si engine in-cylinder pressure development for its effect on combustion noise, J Eng Gas Turb Power 120 (3) (1998) 664-668. doi : 10.1115/1.2818197.

[42] J. Chung, J. Oh, M. Sunwoo, A real-time combustion control with reconstructed in-cylinder pressure by principal component analysis for a crdi diesel engine, J Eng Gas Turb Power 139 (6) (2017) 062802. doi: 10.1115/1.4035395.

[43] S. Som, S. Aggarwal, Effects of primary breakup modeling on spray and combustion characteristics of compression ignition engines, Combust. Flame 157 (6) (2010) 1179-1193. doi:10.1016/j.combustflame. 2010.02.018.

[44] Z. Han, R. D. Reitz, Turbulence modeling of internal combustion engines using rng $\kappa-\varepsilon$ models, Combust. Sci. Technol. 106 (4-6) (1995) $267-$ 295. doi : 10. 1080/00102209508907782.

[45] A. E. W. Austen, T. Priede, Origins of diesel engine noise, SAE Technical Paper 590127. doi : 10.4271/590127.

[46] L. Stanković, J. F. Böhme, Time-frequency analysis of multiple resonances in combustion engine signals, Signal Process. 79 (1) (1999) 15-28. doi : 10. 1016/S0165 - 1684 (99) 00077- 8.

[47] A. J. Shahlari, C. Hocking, E. Kurtz, J. Ghandhi, Comparison of Compression Ignition Engine Noise Metrics in Low-Temperature Combustion Regimes, SAE International Journal of Engines 6 (2013) 541-552. doi : 10.4271/2013-01- 1659.

[48] A. Broatch, X. Margot, R. Novella, J. Gomez-Soriano, Impact of the injector design on the combustion noise of gasoline partially premixed combustion in a 2-stroke engine, Appl. Therm. Eng. 119 (2017) 530 540. doi:10.1016/j . applthermaleng . 2017.03.081.

[49] A. Broatch, R. Novella, J. García-Tíscar, J. Gomez-Soriano, Potential of dual spray injectors for optimising the noise emission of gasoline partially premixed combustion in a 2-stroke HSDI CI engine, Appl. Therm. Eng. (2018) 369-378doi : 10 . 1016/j . applthermaleng . 2018. 01.108.

[50] D. Anderton, Relation between combustion system and engine noise, SAE Technical Paper 790270. doi : 10.4271/790270.

[51] M. F. Russell, R. Haworth, Combustion Noise from High Speed Direct Injection Diesel Engines, SAE Surface Vehicle Noise and Vibration Conference 850973. doi: 10.4271/850973.

[52] E. G. Giakoumis, A. M. Dimaratos, C. D. Rakopoulos, Experimental study of combustion noise radiation during transient turbocharged diesel engine operation, Energy 36 (8) (2011) 4983-4995. doi: 10 . 1016/j . energy . 2011.05.043. 